\title{
Commentary: Time trends of cancer incidence in Campania: 25 years of observation
}

\author{
Paolo Indolfi ${ }^{*}$, Serena Picazio ${ }^{2}$, Silverio Perrotta ${ }^{1}$, Francesca Rossi ${ }^{1}$, Andrea Pession ${ }^{3}$, Martina Di Martino ${ }^{1}$, Elvira \\ Pota', Daniela Di Pinto', Roberto Rondelli ${ }^{3}$, Cristiana Indolfi', Fiorina Casale' \\ 'UOSD Hemato-Oncology, Department of Woman and Children, and General and Specialized Surgery, University of Campania "Luigi Vanvitelli", Naples, Italy \\ ${ }^{2}$ AlL, Section "Valentina Picazio", Caserta, Italy \\ ${ }^{3}$ Pediatric Hemato-Oncology Unit, University of Bologna, Italy
}

\section{Article Info}

\section{Article Notes}

Received: March 22, 2018

Accepted: June 13, 2018

\section{${ }^{*}$ Correspondence:}

Dr. Paolo Indolfi UOSD Paediatric Hemato-Oncology,

Department of Woman and Children, and General and

Specialized Surgery, University of Campania "Luigi

Vanvitelli", Naples, Italy;

via L. De Crecchio 80138 Napoli. Telephone:

39.81.5665412, Fax: 39.81.294306

E-mail: paolo.indolfi@unicampania.it

(c) 2018 Indolfi P. This article is distributed under the terms of the Creative Commons Attribution 4.0 International License.

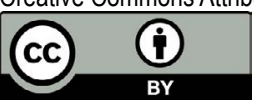

\section{Keywords}

Epidemiology

Cancer

Children

Hematology

Oncology

\section{ABSTRACT}

Introduction: Childhood cancer is relatively uncommon and the European age-standardized rate was 164 new case per million per year among 0 to 15 years old children (95\% Cl 158-170). We analyzed data collected in the Mod. 1.01 of the AIEOP (Association Italian Pediatric Hematology-Oncology) over 25 years (1990-2014) about patients with malignant disease diagnosed in 90 towns of the "Ground of fires" (56 in Napoli and 34 in Caserta province).

Methods: Thanks to the wide monitored population we defined 5 time trends: 1990-94; 1995-99; 2000-04; 2005-09; and 2010-14. We calculated the ratio between observed cases $(O)$ and expected $(E)$ numbers of cases among the children from "Terra dei fuochi".

Results: 2037 cancer patients (0-15 years) were registered in the AIEOP database: 1144 males (56.1\%) and 893 females (43.8\%).

Conclusions: It is note-worthy to underline that our cases needed to be integrated with the Hospital Informative System and Register of births, marriage and deaths to have a better collection of observed cases. This is a limit of our study. The data analysis do not show significant differences in number of observed cases and type of diseases respect to our previous epidemiological study on cancer cases registered in Campania.

\section{Introduction}

In the published study we reported the patients with malignant disease observed in 25 years (1990-2014) considering the specialized registry, the Mod. 1.01 of the AIEOP (Association Italian Pediatric Hematology-Oncology). Thanks to the large number of monitored individuals we could define five time trends: 1990-94: 1995-99; 2000-04; 2005-09; and 2010-14. 3655 malignant cancer cases were reported: in Naples (2059 cases), Salerno (625), Caserta (589), Avellino (229), and Benevento (153). The World Health Organization (WHO) highlighted that children are more susceptible to environmental hazards than adults people because of physiological factors and development related characteristics, that seem to enhance the toxic effects of environmental pollutants. Moreover, nowadays more and more children live in the polluted areas and are therefore exposed to carcinogens.Given the relative rarity of cancer in childhood and its high survival rates, the study of cancer incidence in children is the most appropriate outcome indicator. For this reason we evaluated the incidence of the malignant diseases in a population 
of 0-15 years old children from Napoli and Caserta " Terra dei fuochi", after involuntary exposure to environmental pollutants. However, it is worth remembering that a correlation between pollution and cancer requires several types of evidence and a systematic approach following welldefined criteria and methods. For this report we selected all cancer cases diagnosed in the $0-15$ years age group. The age specific rates were computed dividing the number of newly diagnosed cases in a period in this group of age of population by the corresponding population in the same period. The rates defines the mean of diagnoses in one year and is referred to $1,000,000$ subjects of the specific age group. The European age-standardized rate was 164 new cases per million children per year (95\% CI 158-170) $)^{1,2}$ Instead, the annual incidence rate in adolescents (15-19

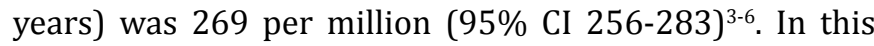
study we reported the number of patients with malignant disease diagnosed before their $15^{\text {th }}$ birthday and observed in 25 years (1990-2014), based on the specialized registry, the Mod. 1.01 of the AIEOP (Association Italian Pediatric Hematology-Oncology). This centralized archive, called Model (Mod.) 1.01, is used since 01.01.1990 and records essential standardized information about all cases of childhood cancer in a 0-19 years old population, diagnosed and/or treated in the AIEOP centers.

\section{Methods}

We started our analysis in 1990 even if we recognize the limits of the Mod. 1.01 as a potential cancer archive. An study was designed for the period 1989-1998, with the aim to compare the new recruited cases with the expected ones (O/E ratio) considering the incidence rates measured by the Childhood Cancer Registry of Piemonte. Results showed good correspondence ${ }^{7}$. Until 2000 the $0 /$ E ratio showed an $8 \%$ deficit in children affected by cancer aged $0-15$ years (O/E 0.92; 95\% CI 0.90-0.95). For this reason we analyzed our data by statistical method since 2000. The CochranArmitage exact test was used to assess the trend incidence. The Breslow-Day test was used to assess 0/E trends. Thanks to the large number of monitored individuals we could define five time trends: 1990-94, 1995-99, 2000-04, 2005-09, and 2010-14. The evaluation of expected cases is related to the number of children from 90 town in "Terra dei fuochi" (56 in Naples and 34 in Caserta). The number of residents in Naples is 2,418,440, while in Caserta there are 621,153 residents (ISTAT 2014). IN detail, in Naples the number of children belonging to each diagnostic period is $534,552,518,942,499,580,467,920$, and 439,137 (DEMOISTAT Registry for population). Based on these data the expected cancer cases were of $515,500,409,383$, and 331 cases, respectively. Instead, in Caserta there are 128,681, $123,829,121,887,117,015$, and 115,583 people in the five diagnostic periods. Related to these numbers the expected cases of cancer cases in this territory were 124, 119, 99,
95, and 87 cases in the same periods analyzed. We have calculated the number of observed cases (0) in all areas of "Terra dei fuoch" and then we have analyzed the ratio between observed and expected (E) numbers of cases. Our aim is to analyze the $0 / \mathrm{E}$ ratio over time and to verify an excess of malignant cancer cases observed in the specific 5-year time in "Terra dei fuochi".

\section{Results}

Global analysis: During the study period 2037 cancer patients (0-15 years) were registered in the AIEOP database, 1144 males (56.1\%) and 893 females (43.8\%). Epidemiological data suggest that about 2138 cases in this territory could be expected during the same period (19902014).

O/E Ratio cases for each province of residence at diagnosis and period of observation: Based on the number of children resident in the 90 towns examined and the expected cases of malignant neoplasm along a 5-years period we showed in the table 1 the $0 / E$ ratios in the five diagnostic periods considered, differentiated for the 56 towns of Naples and the 34 towns of Caserta. The overall 0/E ratio gradually increased from the first period to the last one and was particularly high $(>1)$ in the last 5-year time.

\section{Discussion}

The present findings update descriptive cancer epidemiology in children (0-15 years) in "Terra dei fuochi" in the period 1990-2014 (25 years of observation) based on data provided by specialized clinical Mod.1.01 from AIEOP centers. The expected cancer cases in Campania in this period were calculated using the last AIRTUM's site-specific incidence rates by age group (0-15 years) and were about 4,100 cases (11.5\%), of which $29.7 \%$ were leukemias, $14.5 \%$ were lymphomas, $20.4 \%$ were CNS tumors, and $35.4 \%$ were solid non CNS cancer. These percentages bring about a number of expected cases per year of 51 cases of leukemia, 25 cases of lymphoma, 35 cases of CNS tumours, and 61 cases of solid cancer non CNS. These numbers seems to be similar to our data registered in the "Terra dei fuochi" during the period of observation, with a $48.8 \%$ of emo-lymphoproliferative diseases and $51 \%$ of solid tumors. It is note-worthy to underline that our cases were enrolled from the model 1.01 of AIEOP but they should integrate with the Hospital Informative System and Register of births, marriage and deaths to have a better collection of observed cases. This is a limit of our study. The data analysis do not show significant differences in number of observed cases and type of diseases respect to our previous epidemiological study on cancer casesregistered in Campania ${ }^{8}$. Another consideration is that since 2000 the number of 0-15 years old children with cancer diagnosed and/or registered on Mod.1.01 and then treated in one of the AIEOP center is satisfactory ( $92 \%$ of the total expected) 
Table 1 Ration between observed and expected cases by province of residence at diagnosis and period of observation

\begin{tabular}{|c|c|c|c|c|c|c|c|c|c|c|c|c|c|c|c|c|}
\hline \multirow[t]{2}{*}{ Province } & \multicolumn{3}{|c|}{$\begin{array}{c}I \\
(1990-1994)\end{array}$} & \multicolumn{3}{|c|}{$\begin{array}{c}\text { II } \\
(1995-1999)\end{array}$} & \multicolumn{3}{|c|}{$\begin{array}{c}\text { III } \\
(2000-2004)\end{array}$} & \multicolumn{3}{|c|}{$\begin{array}{c}\text { IV } \\
(2005-2009)\end{array}$} & \multicolumn{3}{|c|}{$\begin{array}{c}V \\
(2010-2014)\end{array}$} & \multirow[t]{2}{*}{$\mathbf{p}^{*}$} \\
\hline & $\mathrm{O}$ & $\mathrm{E}$ & $\mathrm{O} / \mathrm{E}$ & $\mathrm{O}$ & $E$ & O/E & 0 & $E$ & $\mathrm{O} / \mathrm{E}$ & $\mathrm{O}$ & $\mathrm{E}$ & O/E & $\mathrm{O}$ & $\mathrm{E}$ & $\mathrm{O} / \mathrm{E}$ & \\
\hline (56 towns) & 271 & 515 & 0.52 & 297 & 500 & 0.59 & 333 & 409 & 0.81 & 358 & 383 & 0.93 & 360 & 331 & 1.1 & 0.00016 \\
\hline Caserta (34 towns) & 67 & 124 & 0.54 & 68 & 119 & 0.57 & 74 & 99 & 0.75 & 92 & 95 & 0.97 & 117 & 87 & 1.3 & 0,00023 \\
\hline
\end{tabular}

*Breslow-Day test for trend (used to calculate the data from 2000 to 2014)

$\mathrm{O}$ : observed case; E: expected cases $/ 5$ years

without significant differences between Napoli and Caserta. It is important to underline that in both provinces an $0 / E$ ratio $>1$ in the last 5 -year time was observed but further investigations are needed (Table 1).

\section{Funding}

This study was supported by a non-restricted grant by Section Association Italian against Leukemia and Lymphoma (AIL) "Valentina Picazio"-Caserta. The AIL had no role in the design and conduct of the study; collection, management, analysis, and interpretation of the data; preparation, review, or approval of the manuscript; and decision to submit the manuscript for publication.

\section{References}

1. Pritchard-Jones K, Kaatsch P, Steliarova-Foucher E, et al. Cancer in children and adolescents in Europe: developments over 20 years and future challenges. Eur J Cancer. 2006; 42: 2183-90.
2. Kaatsch P. Epidemiology of childhood cancer. Cancer Treat Rev. 2010; 36 (4): 277-85.

3. Gatta G, Zigon G, Capocaccia R, et al. EUROCARE Working Group Survival of European children and young adults with cancer diagnosed 1995-2002. Eur J Cancer. 2009; 45: 992-1005.

4. Ferrari A, Dama E, Pession A, et al. Adolescents with cancer in Italy: entry into the national cooperative pediatric oncology group AIEOP trials. Eur J Cancer. 2009; 45; 328-34.

5. AIRTUM Working Group CCM AIEOP Working Group Italian Cancer Report 2012: Cancer in children and adolescents. Epidemiol Prev. 2013; 37 (1) (I Suppl): 1-296.

6. Pession A, Rondelli R. I tumori dei bambini e adolescenti in Italia. Prospettive in Pediatria. 2013; 43 (172): 226-32.

7. Pession A, Dama E, Rondelli R, et al. Survival of children with cancer in Italy,1989-1998. A report from the hospital based registry of the Italian association of pediatric Hematology and Oncology (AIEOP. Eur J Cancer. 2008; 44(15): 2101-5.

8. Indolfi P, Picazio $S$, Perrotta $S$, et al. Time trend of cancer incidence in childhood in Campania region: 25 years of observation. IJP. 2016; 42 (82): 1-7. 